\title{
LA REFORMA DEL PROCEDIMIENTO ORDINARIO DE NOMBRAMIENTO DEL PRESIDENTE DEL GOBIERNO
}

\author{
IGNACIO TORRES MURO \\ Catedrático de Derecho Constitucional \\ Universidad Complutense de Madrid \\ Del Cuerpo de Letrados del Tribunal Constitucional
}

SUMARIO

I. Introducción. Planteamiento del problema.

II. La solución española. Un caso claro de investidura parlamentaria.

III. Las alternativas: una indagación de derecho comparado.

IV. En todo caso, la última palabra al Parlamento.

V. Conclusiones. La necesidad del cambio y su coste.

\section{INTRODUCCIÓN. PLANTEAMIENTO DEL PROBLEMA ${ }^{1}$}

Los cambios de mayoría al frente del Gobierno de España, registrados en el año 2011, han puesto de manifiesto que el procedimiento ordinario de nombramiento del Presidente del Gobierno, que es, sin duda, el decisivo en la formación de este órgano constitucional, resulta demasiado lento para responder a las necesidades de rapidez, casi inmediatez, que suelen hacerse presentes en estos casos, y que han sido especialmente duras en unos momentos de grave crisis económica.

1 Quiero dejar constancia aquí de mi agradecimiento al personal de las bibliotecas de la Facultad de Derecho de la Universidad Complutense, y del Tribunal Constitucional, sin cuya ayuda hubiese sido imposible redactar este trabajo. 
De ahí que se haya hablado en los medios de la conveniencia de acortar los plazos, que han sido hasta ahora habituales, entre el conocimiento de los resultados de la elección, que se produce prácticamente la misma noche de los comicios, aunque estos sean provisionales, y la toma de posesión del nuevo presidente del Gobierno, que suele acontecer más de un mes después ${ }^{2}$.

El largo período de incertidumbre entre ambas fechas es, sin duda, disfuncional, pero viene prácticamente impuesto por las opciones que se tomaron en la Constitución respecto al nombramiento de presidente del Gobierno, y, en concreto, la adopción de un sistema de investidura parlamentaria, en la que el Congreso de los Diputados tiene la palabra decisiva, incluso en los momentos iniciales del proceso.

En este artículo nos preguntaremos si no ha llegado el momento de cambiar este estado de cosas, y cuáles son las alternativas que se pueden encontrar al mismo principalmente en regímenes parlamentarios, análogos al español, pero también en algunos semipresidencialistas.

Hacemos esto en el marco del debate sobre la reforma de la norma suprema que ha vuelto a abrirse en España en los últimos meses, como consecuencia de la aprobación de nuestro segundo cambio constitucional; debate que, sin embargo, dadas las condiciones políticas de base, no creemos que vaya a conducir a las modificaciones, en algunos casos sustanciales, que nuestra ley fundamental necesita. La aportación que realizamos al mismo es, por ello, un tanto desesperanzada, y, desde luego, de un valor muy limitado. Aun así, creemos que se trata de un ejercicio útil de «ciencia-constitucional ficción», pues sirve para recordarnos que existen alternativas a unas soluciones, las de 1978, que ya han revelado serios problemas.

Desde el momento en que vamos a tocar el modo de selección del principal actor de nuestro sistema jurídico-político, lo que parece un juego de científicos desocupados puede convertirse en la semilla de unas discusiones que lleven a superar alguna de las taras que se han manifestado en los últimos tiempos. Con esa intención abordamos la exposición de nuestras ideas.

\section{LA SOLUCIÓN ESPAÑOLA. UN CASO CLARO DE INVESTIDURA PARLAMENTARIA}

No pretendemos sentar cátedra en este breve artículo sobre el procedimiento ordinario de nombramiento de Presidente del Gobierno en nuestro país, y debe permitírsenos remitir a una serie de trabajos, muy autorizados, que han tratado el tema, y que pueden satisfacer la curiosidad del lector que intente documentarse sobre el mis$\mathrm{mo}^{3}$. A nuestros efectos debe bastar con que señalemos que el constituyente español

2 También ha habido aportaciones en medios científicos, en el sentido de acortar los plazos sin proceder a una reforma constitucional. Vd. DELGADO RAMOS «Breves notas sobre una cuestión controvertida: ¿es posible acortar los plazos para la investidura del candidato a Presidente del Gobierno?»; de próxima publicación en la revista Asamblea. Agradezco a su autor que me haya facilitado el manuscrito.

3 Sobre el Presidente del Gobierno en general, el clásico es BAR El Presidente del Gobierno en España. Encuadre constitucional y práctica política, Civitas, Madrid, 1983. También puede consultarse MATEOS Y DE CABO 
optó, probablemente por imitación del modelo de la Ley Fundamental de Bonn, pero teniendo también en cuenta significativas experiencias constitucionales patrias (la de la Restauración, y la de la II República, de manera principal), por diseñar un sistema en el que el Parlamento, el Congreso de los Diputados en concreto, no solamente tuviera la última palabra en cuanto a quien debía ser designado jefe del Ejecutivo, como procede en todos los regímenes parlamentarios, sino que este fuera elegido por la Cámara Baja, estableciéndose, así, la relación de confianza desde el primer momento.

No es de despreciar, como hemos dicho, la influencia en esta decisión de la tendencia a imitar las soluciones alemanas que es patente en todo el texto constitucional, y, sobre todo en la configuración de un régimen de primer ministro a imitación de la Kanzlerdemokratie (democracia de canciller) alemana. Aquí debemos frenar la exposición al respecto porque pretendemos hacer, más adelante, un análisis en profundidad de aquéllas, resaltando las pocas, pero significativas, diferencias que hay con las nuestras.

Sobre lo que nos corresponde profundizar ahora es sobre la historia española en la materia, que creemos que tuvo una gran importancia para el diseño final. Remontarnos a los inicios del constitucionalismo, en la tan celebrada últimamente Constitución de 1812, y en su desarrollo a través de todo el siglo XIX, nos llevaría demasiado lejos. Como de costumbre, es más importante la historia relativamente reciente, y por eso, y por evidentes razones de espacio, vamos a detenernos un poco solo en el sistema de la Restauración (Constitución de 1876) y en el de la II República (Constitución de 1931).

En el primer texto se establecía que «Corresponde...al Rey: $9^{\circ}$ Nombrar y separar libremente a los ministros» (art. 54), sin que existiera constitucionalmente otra responsabilidad ministerial más que la exigible mediante acusación del Congreso y enjuiciamiento por el Senado (art. $45.3^{\circ}$ ), siguiendo el modelo anglosajón del impeachment.

De ello se deduce que lo importante era la práctica del régimen parlamentario que allí se configuraba, práctica en la que era necesaria la confianza de las Cámaras, y que pudo haber conducido a un parlamentarismo sano, si no se hubiese visto viciada por la costumbre de que los ministerios, mediante los mecanismos del caciquismo, fabricasen los Parlamentos tras conseguir de su Majestad la disolución de las Cámaras.

Como ha escrito Lario, en su estudio sobre la primera fase de este período (Alfonso XII y María Cristina), «las Cortes no originaban los Gobiernos, sino a la inversa», y el Rey «debía atenerse, no a las mayorías parlamentarias, sino al acuerdo entre los jefes políticos», e, incluso, "prácticamente al criterio personal, sobre todo pasados los primeros años del gobierno conservador» ${ }^{4}$.

El Presidente del Gobierno en España: status y funciones, La Ley, Madrid, 2006. La exposición del mecanismo de investidura puede verse en REVENGA SÁNCHEZ La formación del gobierno en la Constitución española de 1978, CEC, Madrid, 1988, passim.; y en VINTRÓ CASTELLS La investidura parlamentaria del Gobierno: perspectiva comparada y Constitución española, Congreso de los Diputados, Madrid, 2006, págs. 263 y ss. También conviene leer los comentarios al art. 99 CE contenidos en ALZAGA VILLAMIL (dir.) Comentarios a la Constitución española de 1978, Tomo VIII, Edersa, Madrid, 1998, obra de BAR; y en CASAS BAAMONDE y RODRÍGUEZ-PIÑERO BRAVO-FERRER (Dirs) Comentarios a la Constitución española, Wolters Kluwer, Madrid, 2009, del que es autor VINTRÓ CASTELLS.

4 LARIO El Rey, piloto sin brújula. La Corona y el sistema político de la Restauración (1875-1902), UNED/Biblioteca Nueva, Madrid, 1999, pág. 450. 
El problema se agravó en el reinado de Alfonso XIII, el «político en el trono» ${ }^{5}$, experto en las «crisis orientales» ${ }^{6}$ y el «borboneo» ${ }^{7}$, que acabó por quebrar todo el sistema facilitando el advenimiento de una dictadura, pero que, mientras jugó dentro del mismo, se reservó un papel predominante en el nombramiento de los presidentes del consejo, pues tal era su manera de entender la Constitución de 1876, manera de entender la norma suprema que llevó a todo el entramado constitucional, también evidentemente por otras razones, a una crisis irreversible.

El advenimiento de la II República curiosamente no varió en exceso la implicación del jefe del Estado en el nombramiento del Presidente del Gobierno. Según la Constitución de 1931 (art. 75), el Presidente de la República nombraba y separaba libremente al Presidente del Gobierno, y debía separarlo necesariamente en el caso de que las Cortes le negaran de modo explícito su confianza.

Como vemos, se trataba de un sistema parlamentario en el que la cabeza del Estado tenía mucho que decir en el nombramiento del jefe del gobierno, dado que este debía contar con su apoyo, además de con el de la Cámara. Las circunstancias políticas de la época y, sobre todo, la fragmentación del Congreso de los Diputados, que no fue en ningún momento dominado por un solo partido, facilitaron el reforzamiento del papel de jefe del Estado, la mayor parte del tiempo D. Niceto Alcalá-Zamora, que representó uno muy activo, hasta el punto de que el ingenio popular, por esta tendencia suya a hacer y deshacer gobiernos, entre otras cosas, lo denominó «Don Alfonso en rústica», pues parecía revivir las prácticas de la última fase de la Restauración, presidida, como sabemos, por el Rey Alfonso XIII. La interpretación, y aplicación, del art. 75 que hizo D. Niceto «acabó configurando un régimen parlamentario de doble confianza» ${ }^{8}$.

Canales Aliende lo ha expresado con claridad, al decir que el protagonismo en estas materias del señor Presidente «recordaba al destronado monarca, sobre todo a la hora de nombramientos de miembros del Gobierno, queriendo nombrar ministros de su confianza personal o de fácil manejo al margen de las coaliciones parlamentarias» ${ }^{9}$.

Este breve repaso de nuestra historia constitucional más reciente, caracterizada en el terreno que nos ocupa por una disfuncional intervención del jefe del Estado en la formación de unos gobiernos que debieron, ante todo, haber sido responsables ante la Cámara de representación popular, creemos que puede explicar por qué el constituyente de 1978 optó por reservarle al mismo un papel de simple cooperador en el proceso, sustrayéndole las verdaderas decisiones, y poniéndolas en manos del Parlamento.

5 MORENO LUZÓN (ed.) Alfonso XIII. Un político en el trono, Marcial Pons, Madrid, 2003. Sobre este período ver también GARCÍA QUEIPO DE LLANO «La crisis de la monarquía constitucional. Alfonso XIII en su tiempo»; en TUSELL, LARIO, y PORTERO (eds.) La Corona en la historia de España, Biblioteca Nueva, Madrid, 2003.

6 Se denominaban sí, en la Restauración, las crisis ministeriales que tenían su origen en la voluntad del Rey, que, recuérdese, residía entonces en el Palacio de Oriente.

7 «Borbonear» era la intervención del Rey — un Borbón— en la vida política, jugando con los actores de la misma para perseguir sus intereses propios.

8 VINTRÓ CASTELLS La investidura...., pág. 212.

9 CANALES ALIENDE «La Jefatura del Estado durante la segunda República»; en VV. AA: Actas del IV Symposium de Historia de la Administración, INAP, Madrid, 1983, pág. 121. 
En realidad puede hablarse de una mezcla de factores, como son la imitación del modelo alemán, sobre el que nos detendremos más adelante, la intención de no repetir los errores de la historia patria, a los que nos acabamos de referir, y también el hecho muy importante de que en la Constitución de 1978 se ponía a la cabeza del Estado a un Monarca hereditario, y no a un Presidente de la República elegido, de una manera más o menos directa, por el pueblo soberano.

Esta opción, en el modo actual de entender la Monarquía, que tuvo una influencia clara sobre nuestros constituyentes, supuso que se considerara necesario implicar lo menos posible al titular de la Corona en el juego político diario, y no cabe duda de que la decisión sobre quién ha de ser el Presidente del Gobierno es una de una carga política muy importante, de la que aquél debe mantenerse, en la medida de lo posible, al margen.

Del examen de los debates constituyentes Revenga ha deducido que «el acuerdo fue total en el aspecto de descartar...la asunción de funciones ministeriales sin necesidad de una explícita manifestación parlamentaria de confianza» ${ }^{10}$, y que se excluyó la «posibilidad de investiduras parlamentarias implícitas a la manera del parlamentarismo "negativo" de algunas Monarquías europeas» ${ }^{11}$.

El resultado es, de todos, conocido, y ciertamente novedoso en nuestra historia constitucional, como apuntó Alzaga en su momento ${ }^{12}$. Un art. 99 CE en el que el Monarca — del que se ha dicho que en este caso no ejerce poderes de dirección política, sino arbitrales ${ }^{13}$ - , tras evacuar consultas con los líderes de los grupos con representación parlamentaria, propone, con el refrendo del Presidente del Congreso de los Diputados, a la Cámara Baja un candidato que debe ser investido por mayoría absoluta en primera votación, y por mayoría simple en una segunda, y que si supera este escollo es nombrado Presidente del Gobierno por el Rey, de nuevo con el refrendo del Presidente del Congreso. No ha faltado quien considera la previsión de la facultad de propuesta del Monarca como una «imprudencia....manifiesta» ${ }^{14}$, pero ya veremos como en otras monarquías, igualmente parlamentarias, los reyes gozan incluso de más poderes sobre el papel.

Una elección, por tanto, en manos del Parlamento, que ha presentado el inconveniente de que los plazos necesarios para el desarrollo del proceso son muy dilatados como consecuencia de la necesidad de que se encuentre constituido el Congreso, y de otros factores. Lo que haremos a continuación es examinar las soluciones diferentes, a este problema, que existen en los regímenes parlamentarios, y semipresidenciales, de nuestro entorno, por si de ellas pudieran derivarse algunas enseñanzas para la experiencia propia.

10 REVENGA SÁNCHEZ, op. cit. pág. 23.

11 Op. ult. cit. pág. 342. Ver también como no hubo alternativa a la investidura parlamentaria en los debates constituyentes, en MATEOS Y DE CABO, op. cit. págs. 123 y ss.

12 ALZAGA La Constitución española de 1978 (comentario sistemático) Ediciones del Foro, Madrid, 1978, pág. 625.

13 DE CARRERAS SERRA «Significado constitucional de la monarquía parlamentaria» en TUSELL, LARIO, y PORTERO (Eds.), op. cit., pág 247.

14 PÉREZ ROYO «La Corona y el Gobierno en la Constitución española»; en VV. AA: VII Jornadas de Derecho Parlamentario: la Monarquía parlamentaria, Congreso de los Diputados, Madrid, 2001, pág. 164. 


\section{LAS ALTERNATIVAS: UNA INDAGACIÓN DE DERECHO COMPARADO}

Ya conocemos el estado de la cuestión en España, y, dado que parece necesario buscarle alternativas, creemos que lo mejor es hacer un repaso a las soluciones en derecho comparado en cuanto al nombramiento de primer ministro. Zilemenos hizo, en su momento $^{15}$, una investigación histórica, y comparada, sobre esta figura, que en parte sigue siendo útil, pero que hay que completar con los nuevos desarrollos, aunque no pretendemos llegar a su nivel de exhaustividad.

Nosotros, además, vamos a centrarnos en el problema del nombramiento. En el análisis seguiremos la clasificación de Colliard ${ }^{16}$, que distingue entre tres fórmulas para el mismo: a) nombramiento por el Jefe del Estado; b) propuesta por el Jefe del Estado seguida de una investidura; y c) investidura directa por el Parlamento, sin intervención del Jefe del Estado.

En esos tres bloques dividiremos nuestras indagaciones, sin dejar de recoger la reflexión, más politológica, de este mismo autor, y basada en datos estadísticos, de que en la mayoría de los casos, en países, por supuesto, democráticos y con régimen parlamentario o semipresidencial, «el jefe del gobierno había sido designado para ese puesto porque era jefe de un partido que se encontraba en situación de formar gobierno» ${ }^{17}$. El papel del jefe del Estado se limita, en estos supuestos, «a dar carácter oficial a una designación que ha sido hecha sin su participación» ${ }^{18}$. Sobre esta preponderancia final de un partido con mayoría en las Cámaras habremos de volver en su momento.

\section{a) Los sistemas de nombramiento por el Jefe del Estado}

Este es el sistema más habitual en el derecho comparado, y sobre el que más información se puede recoger, dado que son muchos los casos. Es por eso necesario agruparla en los siguientes bloques: uno dedicado al Reino Unido, que merece tratamiento aparte; otro a las monarquías parlamentarias, moldeadas, en gran medida, siguiendo el patrón de éste; otro a las repúblicas parlamentarias, otro a los países con régimen semipresidencial; y el final dedicado al caso particular de la Federación Rusa.

La situación en el Reino Unido, como tantas veces sucede en ese país, es producto de una larga y lenta evolución, que se inicia con la aparición de la figura del Premier en un momento en el que nadie dudaba que su designación correspondía al Monarca, y que este podía hacerla sin tener en cuenta a los Comunes o a los Lores.

Poco a poco, las Cámaras van ganando poder, hasta que en $1834^{19}$ se produce un hecho decisivo: el Rey (Guillermo IV) cesa a su Primer ministro (Lord Melbourne, whig),

15 Nos referimos a ZILEMENOS Naissance et évolution de la function de Premier ministre dans le régime parlamentaire, LGDJ, Paris, 1976, especialmente págs. 47 y ss.

16 COLLIARD «La designation du Premier ministre en régime parlementaire»; en VV. AA. Mélanges offerts a Georges Burdeau. Le pouvoir, LGDJ, Paris, 1977, pág. 89.

17 Op. ult. cit, pág. 89

18 Op. ult. cit. pág. 107.

19 Ver la descripción del caso en MACKINTOSH The British Cabinet, Steven \& Sons, Londres, 1962, págs 112-114. 
a pesar de que este tiene el apoyo del Parlamento, y nombra a quien le parece bien (Peel, tory). Este no consigue dicho apoyo en las siguientes elecciones, y el Monarca debe volver a nombrar a Lord Melbourne.

Se estableció el principio de que el jefe del Gobierno tiene que estar respaldado por los Comunes, y esa fue la última vez que el Monarca nombró con plena libertad, por más que la Reina Victoria y el Príncipe Alberto creyeran que mantenían la misma, como ha documentado Le May ${ }^{20}$.

Con la ampliación del sufragio estas realidades no hicieron sino confirmarse, de modo que, a partir de 1868 , la Reina nombraba al vencedor en las elecciones ${ }^{21}$, con algún caso raro de ejercicio de poder discrecional porque el partido mayoritario no tenía un jefe claro, como ocurrió con Lord Rosebery en $1895^{22}$.

La siguiente crisis del sistema se produjo en $1931^{23}$, cuando se formó un gobierno nacional, excluyendo a parte de los laboristas, y liderado por Mac Donald, que había sido su líder hasta entonces. De ella se dedujo la regla de que el Premier debe ser elegido con la aprobación, y el apoyo, de su partido ${ }^{24}$, y que el Rey no puede ser una fuerza activa en su nombramiento ${ }^{25}$, pues en otro caso su intervención sería inconstitucional ${ }^{26}$.

Ya en la segunda mitad del siglo XX la inexistencia de reglas para elegir un líder en el partido conservador propició la intervención real en las sucesiones de Eden (1957) y MacMillan (1963), cuando no había un candidato claro $^{27}$, pero se ha afirmado que, incluso en esos supuestos, «el papel del monarca...estuvo en realidad limitado a dar sanción formal a las maniobras política de las figuras más relevantes en el partido conservador» ${ }^{28}$.

Parece que la Reina, en todo caso, ha tenido claro que, como ha dicho uno de sus secretarios privados (Aldeane), su obligación era encontrar no el mejor Primer Ministro, sino uno que pudiera controlar la mayoría en los Comunes ${ }^{29}$. Eso le ha servido para enfrentarse al problema de los parlamentos sin mayoría clara (bung parliaments) ${ }^{30}$, nombrando a quien se le presente al frente de una coalición sólida, como ha hecho después de las elecciones de 2010, tras mantenerse al margen de las negociaciones, con el resultado de que «la neutralidad de la Reina no se ha visto comprometida como pudiera haber sucedido si se la hubiese implicado en el proceso de formación del go-

20 LE MAY The Victorian Constitution. Conventions, Usages, and Contingencies, Duckworth, Londres, 1979, pág. 46

21 MACKINTOSH, op. cit. pág. 222.

22 LE MAY, op. cit, pág. 88, para el caso.

23 Ver MOODIE «The Monarch and the selection of a Prime Minister: a re-examination of the crisis of $1931 »$; en Political Studies, vol V, 1, 1957, págs. 1-20.

24 Op. ult. cit. pág. 13 y 20.

25 Op. ult. cit. pág. 18.

26 MACKINTOSH, op. cit. pág. 517.

27 La práctica en estos casos en BLAKE «Constitutional Monarchy: The Prerogative Powers»; en BUTLER, BOGDANOR y SUMMERS (Eds,) The Law, Politics, and the Constitution. Essays in Honour of Geoffrey Marshall, Oxford University Press, Oxford, 1999, págs. 23 y ss. Ver también la detallada descripción de BOGDANOR The Monarchy and the Constitution, Clarendon Press, Oxford, 1995, págs. 84 y ss.

28 THOMAS: Prime Minister and Cabinet today, Manchester University Press, Manchester, 1998, pág. 52.

29 Declaraciones recogidas en PIMLOTT: The Queen, Harper and Collins, Londres 1997, citado por BLAKE op. cit. pág. 22.

30 Sobre las convenciones constitucionales que pudieran regular este supuesto ver G. Marshall Constitutional Conventions, Clarendon Press, Oxford, 1986, págs. 220 y ss. 
bierno» ${ }^{31}$. Como se propugnó ${ }^{32}$, dicha cuestión debe resolverse en Westminster (sede de las Cámaras), y no en Buckingham (palacio real), y así se ha hecho.

La conclusión bien puede ser, como dice Brazier, que hoy en día «la selección de un nuevo Primer Ministro no depende de ningún poder de prerrogativa» ${ }^{33}$. Contra lo que afirmaba en 1982 ese mismo autor, parece que ya es hora de consignar esta parte de la prerrogativa real «al trastero donde yacen las partes descartadas del derecho y la práctica constitucionales» ${ }^{34}$. Los partidos políticos ingleses tienen claro que deben darle el problema resulto a la Reina, y lo han hecho de este modo en los últimos tiempos, de manera que la regla es la que ha venido afirmándose poco a poco desde 1834: quien tiene mayoría en los Comunes, será Primer Ministro.

Este modo de ver las cosas ha tenido gran influencia sobre el resto de las monarquías parlamentarias. Nos referiremos aquí a los casos de Bélgica, y los Países Bajos, que aparecen como especialmente representativos. En ellos, y a pesar de que su Constituciones han sido reformadas hace relativamente poco, la regla que se establece es que «el Rey nombra y cesa a sus ministros» (art. 96 de la Constitución belga) y que «el Primer Ministro y los demás Ministros serán nombrados y cesados por decreto real» (art. 43 de la Constitución holandesa).

Ahora bien, la práctica constitucional, limita una libertad de nombramiento que podría entenderse sin freno alguno, desde el momento en que en ambos países se tiene claro que los gobiernos deben contar con la confianza de las Cámaras. De hecho los procedimientos de formación de Gobierno son bastante complicados, dada la fragmentación habitual en sus Parlamentos.

En Bélgica ${ }^{35}$ se desarrolla todo un sistema de consultas y sondeos, en los que el Monarca es ayudado por «informadores»y «formadores», encargados de conseguir una coalición con apoyo en las Cámaras. Los autores reconocen que la «autoridad investida por la Constitución de la responsabilidad de designar los ministros es incontestablemente el Rey» ${ }^{36}$, y que «representa un papel determinante ${ }^{37}$, de modo que «el nombramiento de un ministro no está sujeto... a la ratificación de las Cámaras legislativas» ${ }^{38}$, en el bien entendido de que aquél «no dispone de una "libertad absoluta" en la elección» de los mismos ${ }^{39}$ y que «la costumbre constitucional exige también que el gobierno goce de la confianza de las Cámaras» ${ }^{40}$.

31 LEYLAND: The Constitution of the United Kingdom. A Contextual Analysis, $2^{\mathrm{a}}$ edición, Hart, Londres y Portland, 2012, pág. 94.

32 BRAZIER: «Constitutional Reform and the Crown»; en SUNKIN y PAYNE The nature of the Crown. A Legal and Policial Analysis, Oxford University Press, Oxford, 1999, pág. 341.

33 BRAZIER: «Choosing a Prime Minister» Public Law, Autumn 1982, pág. 396.

34 BRAZIER, op. ult. cit. pág. 417.

35 Ver, por ejemplo, la descripción de SENELLE Y OTROS en À l'attention de sa Majesté le Roi. La monarchie constitutionnelle et le régime parlementaire en Belgique, éditons mols, Paris, 2006, pgs. 253 y ss. También DELPÉRÉE, que nos ilustra sobre los « usos políticos » en DELPÉRÉE Le Droit Constitutionnel de la Bélgique, Bruylant/LGDJ, Bruselas/Paris, 2000, págs. 420 y ss. Y UYTTENDAELE, Précis de Droit constitutionnel balge, $3^{a}$ edición, Bruylant, Bruselas, 2005, págs. 417 y ss. En castellano VINTRÓ CASTELLS, págs. 107 y ss.

36 DELPÉRÉE, op. cit. pág. 410.

37 UYTTENDAELE op. cir. pág. 417.

38 DELPÉRÉE op. cit. pág. 411.

39 DELPÉRÉE op. cit. pág 414.

40 UYTTENDAELE op. cit. pág. 416. 
En Holanda se reconoce que el Monarca «tiene el liderazgo» ${ }^{41}$ en el proceso de formación del gobierno, igualmente complicado ${ }^{42}$, y que «desempeña un papel especial» ${ }^{43}$ en el mismo, pero está también claro que lo decisivo en la posibilidad de alcanzar el poder es gozar del apoyo de las Cámaras, porque en todas estas monarquías «pese a la falta de expresión del carácter condicionado, reglado o debido de estos nombramientos y ceses...el contenido de poder real de estas provisiones queda prácticamente huero, puesto que indefectiblemente se conectan con el carácter democrático del sistema parlamentario». ${ }^{44}$

Sistemas parlamentarios puros son también los de Italia ${ }^{45}$ y Grecia, aunque el frente de ellos está un Presidente de la República. En el primer país las reglas contenidas en la Constitución son relativamente sencillas, dado que el art. 92 dispone que «el Presidente de la República nombra al Presidente del Consejo de Ministros y, a propuesta de este, a los

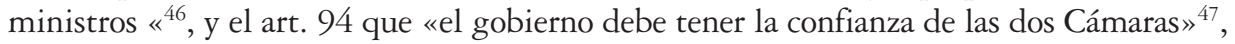
dato este último que, evidentemente, limita los poderes presidenciales de nombramiento, pues el ejecutivo a formar tiene que gozar de suficiente apoyo en las Asambleas.

La práctica desde 1947 ha resultado mucho más complicada, en principio por la existencia de un multipartidismo que hacía del proceso de nombramiento de Presidente del Consejo algo muy atormentado ${ }^{48}$, dado que no resultaba fácil conseguir los apoyos necesarios en el Parlamento, y las diferentes coaliciones posibles se iban sucediendo, a veces a una velocidad de vértigo, provocando una crónica inestabilidad gubernamental. Desde que finalizó el dominio político de la Democracia Cristiana, con De Gasperi, «el papel del Quirinal (palacio donde reside el Presidente de la República, aclaramos) en la formación del gobierno creció» ${ }^{49}$, entre otras cosas porque «las elecciones parlamentarias no

41 KORMANN y BOVEND'EERT: The Kingdom of the Netherlands. An Introduction to Dutch Constitutional Law, Kluwer, Denver/Boston, 1993, pág. 95.

42 Ver op. ult, cit. págs. 93 a 97.

43 Op. ult. cit. pág. 97.

44 COTINO HUESO: «La recepción constitucional del nexo Corona y Poder Ejecutivo en las monarquías europeas»; en ROLLNERT LIERN (dir.) Las Monarquías europeas en el siglo XXI, Sanz y Torres, Madrid, 2007, pág. 95.

45 Ver, en castellano, VINTRÓ CASTELLS, op. cit. págs. 113 y ss.

46 Un comentario global en Giovanni Pitruzzella «Comentario a los artículos 92 y 93 » en G. Branca (a cura di) Commentario della Costituzione Art. 92-96 Il Consiglio dei Ministri, Zanichelli/Il foro italiano, BoloniaRoma, 1994, págs. 1 y ss.

47 Ver el comentario al art. 94 de la Constitución italiana en la obra citada en la nota anterior, págs. 237 y ss, y que es obra de M. Villone. GALEOTTI Y PEZZINI resaltan que el objetivo del proceso de nombramiento de Presidente del Consejo debe ser «establecer un gobierno en situación de obtener la confianza de las Cámaras»; en, de estos autores, Il Presidente della Repubblica nella Costituzione italiana, UTET, Turín, 1996, pág. 38.

48 Un analista de 1970 resaltaba que «el iter seguido para conseguir la formación del gobierno resulta en la práctica bastante más complejo que el esquematizado en la carta constitucional». Vd. Giovanni Rizza Il Presidente del Consiglio dei Ministri, Eugenio Jovene, Nápoles, 1970, pág. 4. En las páginas siguientes describe exhaustivamente el proceso de consultas, el «incarico», y otros aspectos del procedimiento en los primeros tiempos de la República italiana. Otra descripción detallada el sistema de «consultazioni» e «incarico» que se da cuando de las elecciones no ha surgido una mayoría preconstituida en G. U. RESCIGNO Corso di diritto pubblico, séptima edición, Zanichelli, Bolonia, 2002, págs. 406 y ss..

49 RIZZA « Il Capo dello Stato nella forma di governo parlamentare: una rivisitazione »; Diritto e Società no 3 (1992), pág. 420.

50 SANDULLI «Premessa compartistica e alcune brevi considerazioni sul ruolo del nostro Presidente della Repubblica»; en Diritto e Società n 1 (1985), pág 155. 
resultaban determinantes para la elección del Premier» ${ }^{50}$, abriendo «espacios de discrecionalidad para el Presidente de la República» ${ }^{51}$, lo que le dotaba «de una cierta libertad de maniobra» ${ }^{52}$.

A partir las reformas de finales del siglo pasado, que han llevado a hablar de una «Segunda República», y dado que los sistemas electorales ensayados producían ahora mayorías relativamente claras en las Cámaras, la tarea del Presidente de la República se ha simplificado, con un consiguiente reforzamiento de la posición del Presidente del Consejo, a consecuencia de que los ocupantes del cargo no son ya, como sucedía en el pasado, unos meros primus inter pares, sino los verdaderos líderes de una de las dos orientaciones en las que — siendo injustos, pues la realidad es mucho más rica — parece irse dividiendo el país.

El Presidente tiene ahora el papel de «garantizar a la mayoría que ha resultado vencedora en las elecciones el poder de gobierno ${ }^{53}$. Es de resaltar, sin embargo, que estos cambios son producto de los que ha habido en el sistema político de base, porque las normas que regulan el proceso no se han modificado, de modo que la «voluntad de las fuerza políticas es tan decisiva e incluso más que la presidencial, que difícilmente puede ir más allá de sus capacidades de propuesta y de convencimiento» ${ }^{54}$. También que, como consecuencia de la crisis económica, ha aparecido la figura del gobierno «tecnocráticopresidencial», que, en todo caso, tiene que contar con la confianza de la Cámara de Diputados y del Senado.

En Grecia $^{55}$ nos encontramos con unas soluciones similares de nombramiento del Primer ministro por el Presidente de la República (art. 37 de la Constitución) y necesidad de que el gobierno goce de la confianza de la Cámara (art. 84). Ahora bien el papel del jefe del Estado se encuentra limitado por unas reglas muy estrictas en cuanto al procedimiento para designar al jefe del gobierno, contenidas en el primer artículo, que no reproducimos dada su extensión, pero que en síntesis, obliga a aquél a ir encargando la formación del ejecutivo a los cabezas de los grupos que hayan obtenido los mejores resultados electorales, si es que ninguno dispone de la mayoría absoluta de los escaños, en cuyo caso el nombramiento es automático. Como vemos, de nuevo aquí la designación está en manos del Presidente de la República, pero es fundamental la existencia de una clara confianza parlamentaria. Ningún gobierno podría constituirse contra la Cámara.

El caso paradigmático de entre los regímenes semipresidenciales, a los que dedicaremos ahora nuestras reflexiones, es Francia ${ }^{56}$ en donde la norma constitucional se limita también a establecer (art. 8) que «el Presidente de la República nombra al Primer ministro» en un acto exento de refrendo (art. 19), redacción que es la misma que en el original de 1958, pero que ha dado lugar a prácticas diferentes, según ha ido evolucionando el régimen de la $\mathrm{V}^{\mathrm{a}}$ República.

51 TEBALDI Il Presidente della Repubblica, Il Mulino, Bologna, 2005, pág. 153.

52 Op. y loc. ult. cit.

53 CHIOLA «Presidente della Repubblica e formazione del governo «; en LUCIANI y VOLPI (a cura di) Il Presidente della Repubblica, Il Mulino, Bolonia, 1997, pág. 108.

54 BALDASSARRE y MEZZANOTTE «Il Presidente della Repubblica fra unità maggioritaria e unità nazionale» Quaderni Costituzionali n ${ }^{\circ} 1$ (1985), pág.. 24.

55 Un tratamiento más extenso en VINTRÓ CASTELLS, op. cit, págs. 136 y ss.

56 En castellano, VINTRÓ CASTELLS, op. cit. 145 y ss. 
En el apogeo del gaullismo se hablaba sin ambages de una «prerrogativa tradicional del Jefe del Estado», en la que el papel del Parlamento, después de 1962, era «menor»" ${ }^{57}$, hasta el punto de afirmar que el gobierno «procedía» del Presidente de la República ${ }^{58}$, de una libertad de elección «real»s9, y de que nos hallábamos ante un ejemplo de «hecho mayoritario» a la francesa ${ }^{60}$.

El destino del Primer Ministro se encontraba, por tanto, «en manos del jefe del Estado» ${ }^{61}$, se trataba de un nombramiento «personal y discrecional» ${ }^{62}$, considerado una de las raras excepciones a «la regla según la cual el ejercicio de las prerrogativas presidenciales implica la colaboración de otras autoridades» ${ }^{63}$. La clave, sin embargo, la indica Colliard, señalando que estaba en el hecho de que la «mayoría acepta esa situación» y, así, el Presidente «puede ejercer ese poder de manera incondicionada» ${ }^{64}$.

Lo que vino después, con los jefes de Estado no gaullistas, y las cohabitaciones, es ligeramente diferente. Se refleja en los textos más cercanos a nosotros. En ellos se habla ya de «libertad relativa» ${ }^{65}$, de una, sin embargo, «competencia muy amplia» ${ }^{66}$, de una «auténtica función presidencial» ${ }^{67}$, y de una situación en la que puede proponerse un balance, de toda la V ${ }^{\mathrm{a}}$ República hasta 1997 , consistente en que «de quince Primeros ministros, solo seis habrían sido elegidos libremente por el Presidente, tres le han sido impuestos por la derrota, y los otros por las circunstancias de su elección, o de la coyuntura dentro de la mayoría» ${ }^{68}$.

En este nuevo ambiente las soluciones van más bien por la idea de que el Presidente tiene una «competencia discrecional» ${ }^{69}, \mathrm{y}$, sin embargo, debe contar con la presencia de un Parlamento «jurídicamente ausente», pero cuya composición constituye «la mayor limitación que pesa sobre su elección» ${ }^{70}$. De este modo, es él quien «nombra», pero debe tener en cuenta «en su elección la situación parlamentaria» ${ }^{71}$. Este equilibrio lo resumió el Presidente Mitterand, al decir: «no se ponen condiciones al Presidente de la República: el nombra a quien quiere, pero debe actuar conforme a la voluntad popular» ${ }^{72}$.

57 MASSOT «Les rapports du Président de la République et du Premier ministre de 1958 à 1982»; en DUVERGER (dir.) Les régimes semi-présidentiels, PUF, Paris, 1986, pág. 285.

58 DE BAECQUE Qui gouverne la France? Essai sur la répartition du pouvoir entre le chef de l'Etat el le chef du gouvernement, PUF ; Paris, 1976, pág. 83.

59 Op. ult. cit. pág. 92.

60 RIALS Le Premier ministre, PUF, 1981, págs. 79 y 81.

61 CLAISSE Le Premier ministre de la Ve République, LGDJ, Paris, 1972, pág. 55.

62 Op. ult. cit. pág. 60.

63 YOLKA «Le pouvoir de nomination du chef de l'Etat sous la Cinquième République» Revue du Droit Public $n^{\circ} 3$ (1999), pág. 740.

64 COLLIARD, op. cit. pág. 111.

65 FAVOREU Y OTROS Droit constitutionnel, sexta edición, Dalloz, Paris, 2003, pág. 587.

66 FORMERY La Constitution Commentée, duodécima edición, Hachette, Paris, 2008, pág. 29.

67 BRANCHET La fonction présidentielle sous la Ve République, LGDJ, Paris, 2008, pág. 25.

68 PORTELLI «Les Premiers Ministres: essai de typologie», en Pouvoirs no 83 (1997), pág. 23.

69 ARDANT Le Premier Ministre en France, Montchrestien, Paris, 1991, pág. 52.

70 Op. ult. cit. pág. 55.

71 HAMON y TROPER, Droit constitutionnel, trigésima primera edición, LGDJ, Paris, 2009, pág. 636.

72 Citado por RENOUX «L'esperienza francese»; en LUCIANI y VOLPI (a cura di) Il Presidente della Repubblica. Il Mulino, Bologna, 1997, pág. 533. 
Es sabido que hasta las más recientes reformas constitucionales, era relativamente fácil que se produjera una situación de cohabitación, con un Presidente de un color y una mayoría parlamentaria de otro. En esos casos la cosa estuvo pronto clara. «So pena de provocar una crisis grave» el jefe del Estado «está obligado a elegir como Primer ministro» ${ }^{73}$ al líder de esa mayoría, encontrándose con un «poder de nombramiento enteramente atado por la voluntad de la mayoría parlamentaria que le es, por hipótesis, hostil» ${ }^{74}$.

Ya en 2010 la situación se ha resumido diciendo que el Presidente «elige» al Primer ministro, y el Parlamento está llamado a «confirmar la confianza que le ha sido conferida por el jefe del Estado» ${ }^{75}$. En todo caso siempre conviene recordar que, también en el caso francés, «el gobierno es responsable ante el Parlamento» (art 20 de la Constitución) y hay mecanismos para exigir dicha responsabilidad (arts. 49 y ss), por lo que un jefe del gobierno que no tuviera los suficientes apoyos parlamentarios estaría en una situación difícil. Hay que tener en cuenta, finalmente, que la casi coincidencia, de las elecciones presidenciales y las parlamentarias, que se produce en la actualidad, refuerza la posición presidencial como líder de la mayoría, evita la cohabitación, y tiene como consecuencia que los primeros ministros sean «hombres del Presidente».

Aunque la calificación como semipresidenciales de los países que examinaremos a continuación es más discutida, creemos que la etiqueta es cómoda y los diferencia de otras situaciones, como las repúblicas parlamentarias, a las que ya nos hemos referido. En primer lugar, veremos el caso de Portugal ${ }^{76}$. Aquí el Presidente de la República nombra al Primer ministro teniendo «en cuenta los resultados electorales (arts. 133, f, y 187,1 de la Constitución), de modo que no ha habido «gobiernos del Presidente» ${ }^{77}$ y ninguno «ha podido mantenerse en el cargo si no era la emanación o la expresión de la realidad parlamentaria», nombrándose normalmente Primer ministro al «líder político indicado por los partidos» ${ }^{78}$, y estando excluido el nombramiento de «un jefe del gobierno cualquiera, porque goce de la confianza personal propia ${ }^{79} \mathrm{del}$ Presidente de la República.

Gomes Canotilho, por su parte, califica de «propio» el poder presidencial, uno de los que «está autorizado por la Constitución a ejercitar solo y personalmente, incluso cuando están condicionados a la observancia de otras formalidades constitucionales (pareceres, consultas)» ${ }^{80}$, pero no deja de resaltar que «la elección tiene que incidir sobre una persona que pueda beneficiarse de la confianza de la mayoría parlamentaria» ${ }^{81}$. La capacidad de maniobra presidencial es, pues, «reducida» cuando «exista mayoría parlamentaria absoluta o mayoría relativa que tienda a la absoluta» ${ }^{82}$.

73 HAMON y TROPER, op. cit. pág. 637.

74 FAVOREAU Y OTROS, op. cit. pág. 588.

75 BRÉCHON «Francia. Un monarca republicano»; en PASSARELLI (a cura di) Presidenti della Repubblica. Forme di governo a confronto, Giappichelli, Torino, 2010, pág. 101.

76 VINTRÓ CASTELLS, op. cit. págs. 151 y ss.

77 MIRANDA «L'esperienza portoghese»; en LUCIANI y VOLPI (a cura di), op. cit. pág. 523.

78 Op. ult. cit. pág. 525.

79 PASSRELLI «Portogallo. Il Presidente dimezzato?» en PASSARELLI (a cura di) op. cit. pág. 150.

80 GOMES CANOTILHO Direito Constitucional e Teoría da Constituçao, séptima edición, Almedina, Coimbra, pág. 622.

81 Op. ult. cit, pág. 645.

82 OP. ult. cit. pág.. 645. 
La situación en Austria es similar, y de nuevo nos encontramos con la decisiva influencia del Parlamento. Pallaver habla de «absoluta libertad desde el punto de vista formal, pero no...en la praxis política ${ }^{83}$ cuando se refiere a la competencia del jefe del Estado. El art. 70 de la Constitución prevé el nombramiento sin refrendo, pero el Presidente tiene de hecho «poco margen de maniobra» de manera que se «guardará de nombrar un gabinete al que se opone una mayoría parlamentaria» ${ }^{84}$, y solo tiene sentido hacerlo con uno que «no reciba el voto de desconfianza del Parlamento» ${ }^{85}$.

En Polonia se afirma que «el Presidente ha retenido su derecho a designar al primer ministro» ${ }^{86}$ (art. 144.11 de la Constitución), pero en el supuesto de un conflicto «fue forzado a nombrar al candidato preferido por el Sejm (Parlamento)» ${ }^{87}$ y, en todo caso, el Gobierno deberá tener la confianza expresa de este (art. 154,2), que puede elegirlo por sí mismo si no lo ha nombrado el Presidente, o el gobierno presidencial no ha obtenido la confianza (art. 154. 3). En Rumanía el jefe del Estado nombra al Primer ministro, que tiene diez días para obtener la confianza del Parlamento ${ }^{88}$.

Un supuesto muy especial es el del presidencialismo ruso ${ }^{89}$, en el que el nombramiento del Presidente del Gobierno debe contar con el consentimiento de la Duma (Parlamento), pero después de tres rechazos por parte de esta, el Presidente de la República nombra, y disuelve la Duma (art. 109, en relación con el art. 111 de la Constitución de la Federación Rusa), lo que ha dado lugar a situaciones curiosas, en las que los parlamentarios han asumido propuestas que no les gustaban para evitar esa disolución, o el Presidente no ha querido forzar la mano al no estar seguro de los futuros resultados electorales. Un equilibrio inestable que se hubiese evitado si se aplicaran las reglas del presidencialismo puro, en sentido de no someter el nombramiento del jefe del gobierno a la opinión del Parlamento.

\section{b) Los sistemas de investidura con intervención del jefe del Estado.}

Esta manera de solucionar el problema, que estuvo vigente en Francia en la época de la Constitución de $1946^{90}$, en la actualidad es la que, como sabemos, existe en España, en Eslovenia ${ }^{91}$, y en Alemania ${ }^{92}$, que es su ejemplo más destacado, y al que vamos a dedicar casi en exclusiva la exposición, dada su indudable influencia sobre el modelo de nuestro país.

83 PALLAVER «Austria. (Semi) presidenzialismo di facciata e gigante incatenato»; en PASSARELLI (a cura di), op. cit, pág. 217. Un punto de vista jurídico formal en BERCHTOLD Der Bundespäsident, Springer Verlag, Viena/Nueva York, 1969, págs. 218 y ss.

84 MÜLLER «Austria»; en ELGIE (ed.): Semi-Presidentialism in Europe. Oxford University Press, Oxford, 1999, pág. 29.

85 SCHÄFFER «L'esperienza austriaca»; en LUCIANI y VOLPI (a cura di), op. cit., pág. 563.

86 VAN DER MEER KROK-PASZKOWSKA «Poland»; en ELGIE (ed), op. cit. pág. 185.

87 Op. ult. cit. pág. 179.

88 Ver VERHEGEN «Romania»; en ELGIE (ed.), op. cit. págs. 198-199.

89 Ver HENDERSON: The Constitution of the Russian Federation. A Contextual Analysis, Hart, Oxford y Portland, 2011, págs. 113-115.

90 Ver VINTRÓ CASTELLS, op. cit. págs. 68 y ss.

91 CESAK «Slovenia»; en ELGIE (ed.) op. cit. págs. 242-243.

92 Ver, en castellano, VINTRÓ CASTELLS, op. cit. págs. 72 y ss. 
Lo primero en lo que la doctrina es unánime es en que la principal explicación de las reglas de la Ley Fundamental alemana es el intento de separarse radicalmente de las soluciones históricas y, más concretamente de las de la Constitución de Weimar, en la que el Presidente del Reich ${ }^{93}$, elegido directamente por el pueblo, designaba libremente al Canciller, con la consecuencia, provocada también por la fragmentación del Reichstag (Parlamento), de que fuera frecuentes los gobiernos "presidenciales», no apoyados con claridad por una mayoría parlamentaria. Esto provocó un debilitamiento de la democracia que, se sostiene, «favoreció la dictadura y el advenimiento del Tercer Reich» ${ }^{94}$

Se trataba de «disminuir claramente la influencia del Presidente federal en comparación con el Presidente del Reich, y colocar la formación del gobierno en general sobre unas nuevas bases de legitimación ${ }^{95}$, de acabar con una situación en la que «la elección y el nombramiento de los cancilleres» era hecha «solo a través del Presidente del Reich» ${ }^{96}$.

El resultado ha sido que, como escribió gráficamente Herzog, que además ejerció de Presidente federal, «la elección del canciller federal es, por tanto, por primera vez en la historia constitucional de Alemania, y en exclusiva, cosa del Parlamento» ${ }^{97}$. En eso insisten todos los comentaristas, que ven al Bundestag como «garante de la formación de un Gobierno» ${ }^{98}$ y hablan de "prevalencia de la voluntad parlamentaria sobre la presidencial» ${ }^{99}$.

El procedimiento ordinario de nombramiento de canciller viene regulado en el artículo 63 de la Ley Fundamental, y consiste en una propuesta del Presidente que es asumida, o no, por el Bundestag, por mayoría absoluta, en votación secreta y sin debate. En caso de no ser así, la Cámara puede elegir un candidato no propuesto por el jefe del Estado. Existe la posibilidad de elección de un canciller minoritario, en una segunda votación, pero aquí se prevé la alternativa de la disolución. En todo caso, el nombramiento corresponde al Presidente.

La propuesta, que tiene lugar normalmente tras las correspondientes consultas, de cierta importancia porque sin las mismas «no es pensable un ejercicio con sentido del po-

93 Sobre el ReichsPräsident ver, en francés, las síntesis de SCHULZE «La position du Président du Reich dans la République de Weimar» y SHIRMER «Le rôle du Président dans une République sans républicains»; en DUVERGER (dir.), op. cit. págs 113 a 121, y 123 a 131, respectivamente. En italiano las páginas que le dedica THAULERO Il ruolo del Cancelliere federale secondo la Legge Fondamentale, Ciappichelli, Turín, 1994, págs. 7 y ss.

94 ARNOLD «L'élection et les compétences du Présidente fédéral allemand» Revue du DroitPublic $\mathrm{n}^{\circ} 2$ (1995), pág. 319.

95 UHLE «Comentario al art. 63» en SCHMIDT-BLEIBTREU y KLEIN (Hgs.) GG. Kommentar zum Grundgesetz, décimosegunda edición, Carl Heymanns, Colonia, 2011, pág. 1326.

96 SCHNEIDER y ZEH «Koalitionen, Kanzlerwahl, und Kabinettsbildung»; en SCHNEIDER y ZEH (Hgs.) Parlamentsrechts und Parlamentspraxis, Walter de Gruyter, Berlin/Nueva York, 1989, pág. 1305. Sobre el nuevo concepto de jefe del Estado en la Ley Fundamental, y sus diferencias con la situación de Weimar, ver en general SCHLAICH «Die Funktionen des Bundespräsidenten im Verfassungsgefüge»; en ISENSSEE y KIRCHHOF (Hgs.) Handbuch des StaatsRechts. Tomo II, C. F. Müller, Heidelberg, 1987, págs. 579 y ss.

97 HERZOG «Comentario al art. 63» en MAUNZ Y DÜRIG Grundgesetz Kommentar, Tomo IV, 63, Abril de 1983, página. 3. La misma expresión «Sache des Parlaments» en SCHNEIDER y ZEH, op, cit. pág. 1305.

98 SCHRÖDER, «Comentario al art. 63»; en VON MANGOLDT, KLEIN, Y STARCK (Hgs.) Kommentar zum Grundgesetz, Tomo II, sexta edición, Franz Vahlen, Munich, 2010, pág. 1618.

99 THAULERO, op. cit. pág. 19. 
der de propuesta del Presidente federal en un sistema de partidos pluralista» ${ }^{100}$, es concebida como un «derecho» y una «obligación» ${ }^{101}$ y se subraya que no es «personal» ${ }^{102}$. Se realiza mediante una iniciativa formal, que en las condiciones actuales (tendencia al bipartidismo, coaliciones claras, y elecciones plebiscitarias) aparece como «vaciada» ${ }^{103}$, puesto que se trata de una «libertad teórica», que debe «respetar la decisión política que deriva de los resultados electorales» ${ }^{104}$.

Si se ha fijado un acuerdo entre los grupos parlamentarios de la mayoría «el candidato de esta coalición será propuesto y ganará en la primera vuelta, de otro modo será elegido por el Parlamento sin intervención del Presidente federal en la segunda vuelta» ${ }^{105}$. Esta claro que éste deberá sondear «las relaciones de fuerza políticas» y «orientar de acuerdo con ellas su propuesta» ${ }^{106}$.

Su función se ha definido muy gráficamente como la de «asistencia al parto» (Geburtshilfe $)^{107}$. Parece, por tanto, una comadrona que facilita la operación, pero que no es la protagonista principal de la misma. Su papel es importante, pero no el decisivo, que ya sabemos que los constituyentes alemanes quisieron reservar al Bundestag, puesto que como dijo tempranamente Amphoux el rasgo principal del sistema es que la confianza parlamentaria es el «fundamento del poder del Canciller federal» ${ }^{108}$.

Cumplido correctamente todo el proceso la doctrina ha hablado de «deber de nombramiento» del canciller elegido ${ }^{109}$ y eso es efectivamente lo que hace el Presidente: dar solemnidad a lo decidido en otra parte, aunque hay que recordar que todos estos actos están exentos de refrendo ${ }^{110}$.

\section{c) Los sistemas de investidura parlamentaria pura.}

El tercer bloque de esta exposición de derecho comparado lo dedicaremos a la descripción sumaria de aquellos supuestos en los que el nombramiento del jefe del gobierno se produce sin intervenciones ajenas al Parlamento; es decir, estamos ante sistemas de investidura en los que el jefe del Estado no interviene más que para solemnizar el resul-

100 SCHENK «Comentario al art. 63»; en Bonner Kommentar zum Grundgesetz, C. F. Müller, Heidelberg, Noviembre de 1977 , pág. 19.

101 UHLE, op. cit. pág. 1327.

102 TAHULERO, op, cit. pág. 18.

103 SCHNEIDER y ZEH, op. cit. pág. 1310.

104 GRIMALDI «Germania. Il Presidente federale»; en PASSARELLI (a cura di), op. cit. pág. 235.

105 SCHEFOLD «L'esperienza tedesca»; en LUCIANI y VOLPI (a cura di), op. cit. pág. 587.

106 STERN Das Staatsrecht der Bundesrepublik. Deutschland, Tomo II; C. H. Beck'sche, Munich, 1980, pág. 252.

107 UHLE, op. cit. pág. 1327; STERN, op. cit. pág. 251; SCHRÖDER, op. cit. pág. 1624; SCHRÖDER „Bildung, Bestand und parlamentarische Verantwortung der Bundesregierung « en ISENSSE y KIRHCHOF (Hgs.) op. cit. págs. 607 y 608.

108 AMPHOUX Le Chancelier Fédéral dans le Régime constitutionnel de la République Fédéral d'Allemagne, LGDJ, Paris 1962, pág. 18. Se trata de un completo análisis, hecho a principios de los sesenta del siglo pasado, de los problemas que hemos visto, sobre todo en las págs. 33 y ss. En alemán una síntesis de estos asuntos en el comentario de PIEROTH al artículo 63 que se contiene en JARASS y PIEROTH: GG. Grungesetz für die Bundesrepublik Deutschland. Kommentar, segunda edición, C. H. Beck, Munich, 1992, págs. 552 y ss.

109 SCHRÖDER «Comentario.....», op. cit. pág. 1629.

110 NIERHAUS Entscheidung, Präsidialakt, und Gegenzeichnung, Franz Vahlen, Munich, 1973, págs. 156 y ss, y 165 y ss. 
tado final, nombrando al elegido, y, a veces, ni eso. Nos detendremos en los casos de Suecia, Finlandia, Irlanda, y Japón.

En el primer país lo que ha sucedido es que, a partir de 1975, se excluye al Rey del procedimiento de investidura, sustituyéndolo por el Presidente del Parlamento (Riksdag). En la Ley sobre la forma de gobierno (Capítulo VI, arts. 1 a 4) se diseña un proceso en el que dicho Presidente propone, tras consultas, un candidato (art. 2), y si la Cámara le concede la confianza (arts. 2 y 3), lo nombrará «en nombre de la asamblea» (art. 4).

Como vemos, se trata de un iter totalmente parlamentario en el que el jefe del Estado solamente está presente en la reunión de constitución del nuevo gobierno (art. 4). La doctrina $^{111}$ ha resaltado sobre todo que el monarca no participe en el procedimiento, pero también el hecho de que la investidura puede obtenerse, y de hecho se ha obtenido en algunos casos, simplemente porque no se opongan a la misma la mitad de los miembros. El artículo dice textualmente que la propuesta del Presidente del Riksdag «será rechazada si más de la mitad de sus miembros emiten contra ella un voto desfavorable, de lo contrario será aprobada» (art. 2).

Pero lo que más nos interesa a nuestros efectos es que el sistema prescinde del jefe del Estado y se encuentra totalmente "parlamentarizado», atribuyéndosele aquí la función de propuesta de candidato («auxilio al parto», a la alemana), al Presidente de la Cámara.

No es el único caso en que esto sucede, pues, en Japón ${ }^{112}$, es también el Presidente de la Dieta el que propone, tras consultar con el Gobierno en funciones, un candidato, para que la Cámara elija, y, en esto se conserva cierto respeto por el jefe del Estado, el Emperador nombra, aunque debe quedar claro que éste «se limita a formalizar un acto debido», pues la elección se ha realizado «conforme a la designación (shimei) de la Dieta» ${ }^{113}$.

De nuevo se excluye la posibilidad de que la comadrona sea el jefe del Estado, por razones históricas (implicación de Hiro Hito en la política imperialista de Japón antes y durante la II Guerra Mundial) que han tenido mucho peso en el diseño de la Constitución de 1946.

Nos queda hacer por fin referencia a otros dos casos de fuerte parlamentarización del procedimiento de nombramiento, en países de modelos constitucionales relativamente cercanos. Nos referimos a Finlandia e Irlanda. En el primero, después de la nueva Constitución del año 2000, el Presidente ha quedado marginado del proceso mediante el cual se elige el Primer ministro, y que consiste en que los grupos parlamentarios designan un «formador», que lleva a cabo las negociaciones conducentes a la formación del gobierno con el resto de las fracciones de la Cámara.

Si consigue éxito en el reparto de las carteras, y en la fijación del correspondiente programa, será adoptado como candidato a jefe del Gobierno por el Parlamento, tras lo cual el Presidente lo nombra sin más trámites ${ }^{114}$.

111 Ver VINTRÓ CASTELLS, op. cit. págs. 92 y ss, y la bibliografía allí citada.

112 Ver op. ult. cit. págs. 65 y ss.

113 RODRÍGUEZ ARTACHO: La Monarquía japonesa, CEPC, Madrid, 2001, pág. 170.

114 Ver. PALOHEIMO «Finlandia. Il progressivo declino dei poteri presidenziali»; en PASSARELLI (a cura di), op. cit. especialmente páginas 128-129. 
En Irlanda ${ }^{115}$ el Taoiseach (Primer ministro) «es elegido para ese puesto por el Dáil (Cámara Baja del Parlamento) y nombrado formalmente para el mismo por el Presidente: art. $13 \cdot 1 \cdot 1^{\circ}{ }^{116}$.

De nuevo vemos como el jefe del Estado se limita «estampillar» una decisión tomada en la Asamblea legislativa, sin participar en el procedimiento, en el que simplemente se discuten sucesivas mociones de los grupos parlamentarios a favor de uno u otro candidato, adjudicándose el cargo a quien obtienen mayores apoyos. Un sistema simple que ha funcionado bien, sin que hicieran falta «comadronas» ni parlamentarias, como en Suecia, ni presidenciales, como en Alemania.

\section{EN TODO CASO, LA ÚLTIMA PALABRA AL PARLAMENTO}

Ya hemos visto las alternativas, derivadas de la experiencia constitucional de los países de nuestro entorno, al sistema español de nombramiento del Presidente del Gobierno. Ahora solo queremos resaltar un dato: en todos los supuestos analizados la última palabra la tiene la Cámara, o las Cámaras, de representación popular, de manera que esta es una de las barreras de cualquier reforma.

Hágase lo que se haga en España, para cambiar nuestros procedimientos, la confianza de la mayoría del Parlamento aparece como básica para cualquier jefe del ejecutivo, derívese ésta de un procedimiento de investidura, más o menos formalizado, o de la tolerancia por parte de la correspondiente Asamblea.

Es verdad que no hemos indagado nada en sistemas presidencialistas, pero esto no tendría sentido, porque en ellos el Parlamento, cuando dice algo sobre los colaboradores de un Presidente que es el verdadero jefe del ejecutivo, lo hace a través de unas comparecencias parlamentarias de control, muchas veces de mera cortesía, y en las que no lleva nunca la iniciativa. No hay que despreciar los posibles resultados de las mismas, pero es evidente que no suponen una participación tan intensa como la que se encuentra en un proceso de investidura.

Puestos a poner todo patas arriba, se podría igualmente proponer un sistema de elección popular directa del Primer ministro, en cuyo caso éste estaría dotado de una legitimidad propia, y podría sustraerse a los controles de las Cámaras, pero esa nueva versión del presidencialismo, referido no al jefe del Estado, sino al del gobierno, no aparece como suficientemente contrastada. Tendría la ventaja, para el problema que nos planteamos, de que el proceso de transición de un ejecutivo a otro podría realizarse con notable rapidez, pero plantearía todos los problemas de relación con el Parlamento que tienen los sistemas presidencialistas, sin tener sus ventajas.

La primera idea que quisiéramos remachar, por tanto, es que no se puede excluir, y de hecho no se excluye en todos los ejemplos que hemos analizado, al Parlamento del juego del nombramiento del Presidente del Gobierno. Otra cosa es cómo se debe articular dicha participación. Si mediante mecanismos de investidura, o, por el contrario, con un

115 Ver VINTRÓ CASTELLS op. cit. págs 60 y ss.

116 CASEY: Constitutional Law in Ireland, Sweet \& Maxwell, Londres, 1987, pág. 139. 
sistema, que hemos visto que es bastante habitual, en el que el jefe del Estado nombre y luego sea necesario confirmar, o al menos ver reconocida de una mera presunta, la confianza de las Cámaras.

\section{CONCLUSIONES: LA NECESIDAD DEL CAMBIO Y SU COSTE}

Y ahora podemos volver, después de todo el recorrido que hemos hecho, al problema que nos ocupa, y que no es otro que en España, dado el sistema de investidura parlamentaria que diseña la Constitución, transcurre un mes o más desde que se conocen los resultados electorales provisionales hasta que toma posesión el nuevo gobierno.

Lo primero que hay que decir es que no somos el único ejemplo de supuestos de larga transición entre un gobierno y otro. Por poner un caso llamativo, esto es lo que viene sucediendo en los regímenes presidencialistas desde hace muchos años. En ellos, la ceremonia de toma de posesión del nuevo jefe del ejecutivo suele acontecer meses después de la elección, como ocurre en su ejemplo más paradigmático: los Estados Unidos.

También es cierto que, hasta ahora, el problema no se había percibido como particularmente acuciante, y solo las especiales circunstancias de crisis, en las que nos movemos actualmente, han llevado a que nos lo planteáramos con toda su radicalidad, desde el momento en que parecía que los mercados castigaban con especial dureza una prolongada situación de gobierno en funciones.

Descartado que pequeñas reformas, de acortamiento de plazos de diversos procesos, nos lleven demasiado lejos, es el momento de debatir sobre una alternativa que, a mi juicio, sería la de confiar al Rey el nombramiento del jefe del gobierno, que podría efectuarse tras una ronda rápida de consultas con las personalidades más significativas, según hayan sido los resultados electorales. Este último debería formar inmediatamente el correspondiente gabinete, que tendría que buscar la confianza del Congreso de los Diputados cuando el mismo se constituyera de una manera definitiva.

De este modo, un proceso que dura más de un mes podría quedar sentenciado en menos de una semana. Ni más ni menos que lo que sucede en gran parte de los países cuyas soluciones hemos examinado, y a los que hemos mirado con cierta envidia cuando sus procesos de transición, de un gobierno a otro, se han resuelto en tan poco tiempo.

Propuesta la alternativa, no podemos dejar de examinar sus ventajas, y sus inconvenientes. La principal ventaja es que se resolvería el problema de lo dilatado de nuestras transiciones. La principal y, prácticamente, la única.

En cuanto a los inconvenientes, creemos que son muchos, y de peso. En primer lugar, que habría que acudir a la, siempre tediosa, en España, vía de la reforma constitucional, si bien, en este caso, a la del artículo $167 \mathrm{CE}$, al no hallarse el mecanismo de investidura entre los contenidos protegidos por el art. $168 \mathrm{CE}$.

En segundo término, aún más importante, que la posible reforma se constituiría contra los trabajados consensos, en esta materia, alcanzados en 1978. No es que consideremos que la Constitución española sea un documento sagrado, que haya que respetar en cualquier caso, pero sí creemos, que, en general, su diseño del poder ejecutivo, y de sus relaciones con las Cortes, fue correcto. 
No conviene olvidar que el retoque propuesto supone también cambiar radicalmente la posición del Rey, que dejaría de ser una comadrona, al estilo alemán, para convertirse en la persona que debe tomar la decisión, todo lo condicionada que se quiera, pero decisión al fin y al cabo, sobre quién debe ser el Presidente del Gobierno; es decir, quién debe ocupar el cargo, sin duda, más importante del sistema constitucional español.

Cabría preguntarse si no sería esto un retroceso en la evolución lógica de las monarquías parlamentarias, caracterizada por la progresiva limitación de los poderes del Rey, que, en el caso de que se llegara a ejecutar la reforma propuesta, recuperaría un protagonismo que tiene en otros países como tributo a una trayectoria histórica sin sobresaltos, y muy diferente de la nuestra, pero del que el constituyente de 1978 huyó con toda lógica, pues se estaba configurando una Corona de finales del siglo XX. No que parece que tenga sentido en el XXI volver atrás como los cangrejos.

Admitiendo, pues, que el cambio sea necesario, y que hay alternativas plausibles, parece que el coste a pagar es demasiado alto. No nos corresponde, como meros técnicos que somos, hacer arriesgadas propuestas de política constitucional. Debemos limitarnos a describir el panorama, y señalar soluciones que tengan sentido, y sean operativas. Pero tampoco puede pedírsenos que nos mantengamos totalmente al margen de los debates que se pudieran suscitar, y en ese sentido creemos que puede decirse que la modificación radical en la posición de la Corona, que supondría el único cambio mediante la que se podría alcanzar una efectiva reforma del procedimiento ordinario de nombramiento del Presidente del Gobierno, es un precio demasiado alto a pagar, que podría desequilibrar todo el sistema, y suscitar algunas tensiones nada aconsejables para el futuro de la institución monárquica.

Sabemos que los dioses de los mercados exigen sacrificios. Alguno se les ha hecho especialmente importante, como el del art. $135 \mathrm{CE}$, aunque parece que no los ha calmado demasiado. Retocar todo el diseño de las relaciones Rey-jefe del gobierno nos parece una decisión excesiva, pues se romperían consensos básicos de la Constitución de 1978.

La conclusión es que no procede cambiar nuestro sistema ordinario de nombrar al Primer ministro. Los problemas que plantea ejecutar las reformas, que exige la alternativa que solucionaría radicalmente las disfunciones observadas, son tales que no merece la pena el esfuerzo. Quizás habría que buscar soluciones en ámbitos que no implicaran tan duros cambios constitucionales. Pero sobre cuáles pudieran ser las mismas no nos corresponde a nosotros pronunciarnos.

$$
* * *
$$

TITLE: The reform of the ordinary procedure to choose the president of the government.

ABSTRACT: The essay makes a review of the debate about a possible reform of the ordinary procedure to choose the primer minister in Spain, in order to make it simpler and quicker. The main solutions to the problem in comparative constitutional law are examined, as a way of fixing the real alternatives, only to conclude that the cost of the reform of the system, that is nowadays working, is to bigh, because it will mean a radical change in the role of the Head of State (the King), and in his relations with Parliament and the ministers.

RESUMEN: El trabajo revisa el debate sobre una posible reforma del procedimiento ordinario de nombramiento del presidente del gobierno en España, con la intención de hacerlo más simple y más rápido. Se examinan las principales soluciones al problema en el derecho constitucional comparado, como una manera de fijar las alternativas reales, solo para llegar a la 
conclusión de que el coste de la reforma del sistema actualmente vigente es demasiado alto, porque significaría un cambio radical en el papel del jefe del Estado (el Rey) y en sus relaciones con el Parlamento y los ministros.

Key Words: Prime minister. Selection, Reform. King. Parliament. Foreign solutions.

Palabras Clave: Presidente del Gobierno. Nombramiento. Reforma. Rey. Parlamento. Soluciones extranjeras.

FECHA DE RECEPCIÓN: 9.06.2012. FeCHA DE ACEPTACIÓN:. 19.07.2012

UNED. Teoría y Realidad Constitucional, núm. 30, 2012, pp. 315-334. 